\title{
Fructose consumption in the Netherlands: the Dutch National Food Consumption Survey 2007-2010
}

In recent years, fructose has been the center of scientific as well as media attention ${ }^{(1)}$. The actual fructose consumption is, however, not clear for many non-U.S. populations. The aim of this study was to estimate the fructose consumption and its main food sources in a representative sample of the Dutch population.

A total of 3,817 men and women aged 7-69 years from the Dutch National Food Consumption Survey 2007-2010 were studied ${ }^{(2)}$. Values for fructose content of products were assigned using food composition tables from the Netherlands, United Kingdom, Finland, and Denmark. Diet was assessed with two non-consecutive 24-hour dietary recalls. Habitual fructose consumption was estimated with the Multiple Source Method ${ }^{(3)}$.

Median habitual fructose intakes are shown in the table.

\begin{tabular}{|c|c|c|c|c|c|}
\hline & Age (y) & $\mathrm{N}$ & Mean \pm SD & Median [IQR] & $\mathrm{En}^{2} \%$ \\
\hline All & $7-69$ & 3,817 & $49 \pm 20$ & $46[35-60]$ & $9 \pm 3$ \\
\hline \multirow[t]{5}{*}{ Men } & $7-8$ & 153 & $58 \pm 9$ & $58[46-68]$ & $11 \pm 2$ \\
\hline & $9-13$ & 351 & $61 \pm 12$ & $58[50-71]$ & $11 \pm 2$ \\
\hline & $14-18$ & 352 & $63 \pm 14$ & $61[49-75]$ & $10 \pm 2$ \\
\hline & $19-50$ & 703 & $53 \pm 28$ & 50 [37-66] & $8 \pm 3$ \\
\hline & $50-69$ & 351 & $43 \pm 21$ & $43[30-54]$ & $7 \pm 3$ \\
\hline \multirow[t]{5}{*}{ Women } & $7-8$ & 151 & $56 \pm 8$ & 56 [47-63] & $11 \pm 1$ \\
\hline & $9-13$ & 352 & $57 \pm 10$ & 56 [47-68] & $11 \pm 2$ \\
\hline & $14-18$ & 354 & $52 \pm 11$ & 52 [42-62] & $10 \pm 2$ \\
\hline & $19-50$ & 698 & $45 \pm 22$ & $44[32-55]$ & $9 \pm 3$ \\
\hline & $50-69$ & 352 & $39 \pm 17$ & $38[30-48]$ & $8 \pm 3$ \\
\hline
\end{tabular}

Values are presented as mean \pm standard deviation or median [P25 - P75].

Of total fructose intake, $67 \%$ was consumed as sucrose and $33 \%$ was consumed as free fructose. Soft drinks constituted the main food source of total fructose (13-29\% across age and sex categories), followed by juices (9-12\%), fruit (9-18\%), and cake and cookies $(9-11 \%)$.

Fructose consumption in the general Dutch population was somewhat lower than most recent figures from the U.S. Within the National Health and Nutrition Examination Survey III from 1988-1994, mean fructose intake was estimated at 55 gram/day comprising $10 \mathrm{en}^{\%}{ }^{(4)}$. Considering that soft drinks, cakes, and cookies usually provide excess calories and only few nutrients, lowering its consumption will help to maintain in energy balance.

This research was supported by the Knowledge Centre Sugar and Nutrition, the Netherlands.

1. Rippe JM, Angelopoulos TJ (2013) Sucrose, high-fructose corn syrup, and fructose, their metabolism and potential health effects: what do we really know? Advances in nutrition 4(2), 236-45. Epub 2013/03/16.

2. van Rossum CTM, Fransen HP, Verkaik-Kloosterman J, Buurma-Rethans EJM, Ocké MC (2011) Dutch National Food Consumption Survey 2007-2010. Diet of children and adults 7 to 69 years. RIVM-Report 350050006. Bilthoven: RIVM 2011.

3. Haubrock J, Nothlings U, Volatier JL, Dekkers A, Ocke M, Harttig U, et al. (2011) Estimating usual food intake distributions by using the multiple source method in the EPIC-Potsdam Calibration Study. The Journal of nutrition 141(5), 914-20. Epub 2011/03/25.

4. Vos MB, Kimmons JE, Gillespie C, Welsh J, Blanck HM (2008) Dietary fructose consumption among US children and adults: the Third National Health and Nutrition Examination Survey. Medscape journal of medicine 10(7), 160. Epub 2008/09/05. 